\title{
Investigating the use, adoption and diffusion of Online Social Network adoption (Facebook vs Twitter), within the Older Adult Population (50+) in Hertfordshire UK.
}

\begin{abstract}
This study aims to Identify, understand, examine \& explain the adoption, use \& diffusion of Online Social Network's (OSNs); namely, Facebook vs Twitter within the older population of UK using a quantitative approach, a combination of hard copy and online questionnaires. This study used a random and nonrandom sampling, there were 266 completed replies obtained and analysed using structural equation modelling. This analysis revealed that older adults do not use OSNs for entertainment purposes, but more for effective purposes such as, communication or obtaining news information. It also explains how it provides contributions for academia, policy makers and industrial sectors and offers a conclusion to this paper.

Keywords: Online Social Networks (OSNs), Older Adults, Household Adoption, Diffusion, Usage, United Kingdom.
\end{abstract}

\section{Introduction}

In the last decade Information and Communication Technologies (ICTs) have penetrated daily life as they transform the way society works, communicates, learns, conducts business and interacts; thereby achieving an important role for development [1]. ICTs have proliferated business and government practices and sectors, but at the heart of the ICT revolution is the internet, a revolutionary and complex means of communication [2]. It is also a worldwide, decentralized network of hundreds of computers linked to one another [3], which is not only about computers, but the provision of services, platforms and applications to individuals around the globe. Examples of such platforms include, Facebook, Twitter, LinkedIn, Instagram, and Snapchat that are also known as Online Social Network [4]. Such platforms have largely become part of routine activities. As knowledge of OSN increases, there are also synonymous terms being used for them including, "Social Network Sites (SNS)" or "Social Media". In this paper, we are using the term OSN. In terms of OSN penetration rates within society, Facebook is the most popular OSN as it was the first OSN platform to surpass 1 billion registered accounts with over 2.2 billion monthly active users [5]. Comparatively, twitter also a digital platform that is largely used by celebrities and organizations, has 330 million monthly active users while LinkedIn has 106 million active users [6]. Although ICTs have become significant to society, there is evidence that not all groups of society, which are the older adult population; thereby leading to low adoption within this demographic group of society [7]. ICTs usage among individuals is increasing but still unequally distributed across social groups. Particularly, more sophisticated mobile internet usage such as online banking or transactions with the elderly and less educated are lagging the most [8]. Recognizing that disparities between older adult's user's adoption and use of OSN exists, this research study was motivated to examine the reasons for the differences; thus, the research aim was formed:

To Identify, understand, examine \& explain the adoption, use \& diffusion of OSN; namely, Facebook vs Twitter within the older population of UK.

From the study outcomes, the contributions of this study are viewed to be crucial to areas such as industries, policy makers and academia. From such studies, industry can identify what factors should, or not be emphasized when targeting consumers from this marginal group of society. For policymakers, this research will identify factors to focus on when promoting their online (electronic government) services and factors necessary to provide best practices for safe social networking. To academia, IS theories relating to adoption will be explored and compared to other studies. To familiarize readers to the contents of this paper, the following section explains \& understands the theoretical aspects surrounding this research. This is then followed by a conclusion to this paper that describes the intended research approach as well as the research site to be used for this study and reasons for selecting it.

\section{Theoretical Background}

2.1. United Kingdom: Aging population, Working population and Age of Technology

For this research, older adults are individuals aged 50 years \& above, who have the knowledge and ability of using ICTs and are also known as 'silver surfers' [9]. This categorization from 50 years and above is used as at this age adult's health, cognitive skills \& vision begin to decline. These in turn affect their daily activities and underlying performance [10]. The Office of National Statistics (ONS) found that in 2016, the UK population was at 65.6 million, projected to reach 74 million by 2039. Between 1976 and 2016 there was a 3.8 percentage point increase in the proportion of people aged 65 and over. There are predictions that the older adult population will continue growing to become a quarter of the population by 2046 [11]. The 
population increase is due to growing improvements in the health sector and lifestyle; thus, the use of the term aging population. The aging population has affected not only government operations, but how UK society functions. In 2011, following the implementation of the Equality Act (2010) the UK government abolished the Default Retirement Age (DRA) which was 65 years. These measures are intended to prevent age discrimination in the workplace, and to allow capable older workers the right to continue working if they so choose [12]. To increase employment, several policies were launched targeting older adult's employment; e.g. policy demanded that UK employers employed a further 1 million workers aged between 50 and 69, with the policy aiming to increase GDP by 5\% [13]. A British social attitudes survey showed that financial necessity rose from $34 \%$ to $54 \%$ in individuals reaching the retirement age [14]. The survey results also highlighted reduced percentages (38\% to $8 \%$ ) for individuals continuing to work past the retirement age due to fondness for the job. $80.1 \%$ of men aged 16 to 64 years were in work, considered to be the joint highest employment rate for men since 1991. For women, $71.3 \%$ within the same age range were in work [15]. The increase in the employment rate for women over the last few years has been partly due to ongoing changes to the state pension age for women. This has led to fewer women retiring between the ages of 60 and 65 years. Older worker numbers are growing significantly in the UK, not only due to the growth in population but according to a Centre for Aging better report, using older adult workforces is a solution rather than a problem. The use of an older adult work force in the UK has more positive attributes than negative [16]; i.e. employers consider older employees as valuable assets in aspects such as strong work ethics, reliability, loyalty, business experience, institutional memory and specialized skills. In contrast, few negative remarks have been linked towards the working older population mostly on less adaptability to technological changes and less cognitively capability, which is known as a digital divide [12]. The introduction of the internet has boosted not only connectivity and communication in the UK society, it has led to a massive boost to the economy by creating businesses and unleashing a whole new wave of entrepreneurship [11]. The new age of technology has resulted in mobile internet expansion in the ICT sector that has contributed to a $6 \%$ annual increase between 2000 and 2011 for top ranking firms. Employment in the ICT sector has continued to rise with top firms hiring more than 14 million people worldwide in 2011, a recorded $6 \%$ increase from 2010. Among the top firms, internet sector providers performed the best by generating the best revenue and employment growth
[17]. A key research study commissioned by [18], suggested that investment in broadband (internet) has led to significant benefits for the UK economy. For $\mathrm{UK}$, the increase is recorded at $0.3 \%$ per annum, a cumulative $5.3 \%$ increase over a 15 -year period [19]. In 2016, the UK's total e-commerce sales were at $£ 511$ billion, an increase from 503 million in 2015. Over time the ONS has recorded a large increase in website sales from $£ 60$ billion in 2009 to $£ 128$ billion in 2016 for businesses with over 1,000 or more employees. Companies operating in the UK business sector are adopting the internet: 2016 saw 84\% of all business adopt the internet. Meanwhile, enterprises with 50 or more employees have levels of internet access over $90 \%$ or above [11]. Businesses have continued to evolve and innovate the use of internet particularly in communication with customers. For this, OSN have enabled businesses to improve interactions with customers; thus, promoting themselves online and providing new facilities for marketing their business and recruitment using OSN. The internet is offering diverse online platforms, all operating at the core of evolving digital ecosystems and providing a marketplace for goods, services and information [20], which are delivered both physically and digitally. It is not only private sector enterprises that have been influenced by the internet, but also public sector enterprises have begun to increase their use of the internet. Presently, public sector organizations offer critical current affairs news, schedule meetings in work environments, and recruit using these platforms [21]. In the UK, older adults are considered to be wealth creators because many older adults' are entrepreneurs or are a major work force in the society. However, they are low adopters of ICT, particularly of OSN due to several factors such as risk, trust or userability. Older adults adopting and using OSN do not benefit only in achieving successful and healthy aging; but as entrepreneurs they can offer better customer services, feedback, marketing and other customer focused functions that are now provided using ONS. As it is, societies are viewed to be advancing based on the citizens' capacity to embrace technologies, and the acceptance and usage of these technologies by individuals in general, including older adults is critical for future economies and society [15]. The next section discusses the digital divide gap.

\subsection{Digital Divide}

The growing popularity of OSN among a broader segment of the world's population [22] has influenced social communication means among users. Some research studies base their investigations on the meaning of communication and relationships between OSN users; however, most research into OSN sites focuses on the population of younger people, mainly 
college students ([23]; [24]) as younger population age groups are the most registered and active users of OSN. It is widely acknowledged that young people use OSN such as, Facebook, Instagram, Twitter and LinkedIn more than older adults, leading to an intergenerational "digital divide". As in the case with many other ICTs, such as mobile devices, this distinction has led to a gap known as "Digital Divide". Many research studies and practices acknowledge that it is prevalent in most modern societies [25]. Several studies covering the term "digital divide" within the ICTs context remains broad in the IS sector, but an introduction to fully understand the concept of the digital divide was perfected by [26]. Digital divide in simple terms is the gap between people with access to ICTs and people who do not have access [27]. Another definition of digital divide is the gap between individuals, household, business and geographic areas in different socio-economic levels with regards both to the availability of access to ICT and use of the internet [28]. Several researchers warn against the pitfall of the metaphor "Digital Divide", stating that the metaphor portrays a simple divide between two clearly divided groups such as, e.g. a gap between the older and younger populations adoption and use of OSN and suggest that it is an unfillable gap in society [29]. The rise in the term Digital Divide was at the turn of the century, between 2000 and 2004, where it became an important issue of inequality in the information society of the scholarly and political agenda [29]. However, this led to a shift in attention from physical access to skill access that is observed in terms of a lack of digital skills and awareness among older adult population; thus, highlighting the importance to policymakers the offerings of digital skill training regimes for older adults within society. A research study addressing the age-related digital divide found that the IS literature lacks a comprehensive consideration and explanation of ICT acceptance in general and specifically adoption of OSN among the older population [30]. Research articles such as [31, 32, 33] highlight influential factors leading to digital divide, such as 'age', 'education' and 'health'. Age remains a reoccurring demographic factor predicted to influence OSN adoption and use, this can be linked back to age related issue "cognitive decline" mentioned earlier.

\section{Theoretical Foundations of the} Conceptual Framework used for this study

The phenomena surrounding OSN adoption use and diffusion is researched using developed and tested IS theories and theoretical models. By doing so, the intention is to develop a robust conceptual framework to guide the research. Several theories were considered starting with Theory of planned behaviour (TPB), however due to limitations if used solely for this study other theoretical models were explored. This led to this research using constructs drawn from extensively employed theories such as, Decomposed Theory of Planned behaviour (DTPB), Diffusion of Innovations (DOI) and the Model for the Adoption of Technologies in the Household (MATH) as the research context focuses on technologies used in household such as OSNs. For example, MATH is constructed upon theories drawn from IS, marketing and psychology disciplines by Venkatesh and Brown, [34]. By using MATH theory enables a clear line to be drawn between what drives individuals to adopt household ICTs (e.g. social influence, utilitarian outcomes and hedonic outcome e.tc. and not to adopt household ICTs (e.g. risk and trust) [35]

Constructs drawn from the identified IS models are classified into three groups: Attitudinal beliefs, Subjective Normative beliefs \& Control beliefs, which led to the formation of the hypothesis for this research \& a conceptual model are shown later. Attitudinal Beliefs are an individual's positive or negative feelings when performing a target behaviour [36]. For this research it is linked to MATH and DoI. Subjective Normative beliefs reflect a user's perception that most individuals considered important when determining whether they should, or not perform a certain behaviour [37]; i.e. peer or superior influence on adoption or use of OSN, which is linked to the model MATH. Control Belief that is defined as the extent to which individuals, if they are subjected to do so, believe they can use an innovation or perform a behaviour [38]. Behavioural control is in two forms: self-efficacy \& facilitating conditions. Facilitating conditions are tools such as, time, money and technology needed to make use of an innovation [39]. Control belief will be linked to the models MATH, DTPB and TPB. Also considered in the research conceptual framework are the dependant variables: Behavioural intention, Actual usage and continual intention to use. Behavioural intention for this research captures motivational factors influencing a behaviour and is a recurring variable that can be tested using selected models such as MATH and DPBP. Actual usage and continual intention to use are key elements to investigate within this research. Users of OSN who new adopters will be examined as initial users of OSN and can only be measured using actual behaviour. While the possibility to continue using will be measured using continual intention. For this study, the following hypothesis were formed: Hedonic outcomes: Hedonic outcomes are described as the pleasure derived from the use of PC's [40]. H1i) Hedonic outcomes will have a positive effect on older adult's behavioural intention to adopt and use Facebook. H1iii) Hedonic outcomes will have a positive effect on older adult's behavioural intention to 
adopt and use Twitter. Utilitarian Outcome: Utilitarian Outcome is defined as the degree to which using an ICT (i.e. an OSN such as Facebook) enhances the effectiveness of activities [41]. H2i): Utilitarian Outcomes will have a positive effect on older adult's behavioural intention to adopt and use Facebook. H2ii) Utilitarian Outcomes will have a positive effect on older adult's behavioural intention to adopt and use Twitter. Relative Advantage: Relative Advantage is defined as the degree to which an innovation is technically superior to the technology it supersedes [42]. H3i) Relative Advantage will have a positive effect on older adult's behavioural intention to adopt and use Facebook. H3ii) Relative Advantage will have a positive effect on older adult's behavioural intention to adopt and use Twitter. Complexity: Complexity is the degree to which an innovation is seen by the potential adopter as being relatively difficult to use and understand [43]. H4i) Complexity will have a negative effect on older adult's behavioural intention to adopt and use Facebook. H4ii) Complexity will have a negative effect on older adult's behavioural intention to adopt and use Twitter. Compatibility: Applied from the MATH theory, according to Rogers, [42] is the degree to which an innovation is perceived compatible with existing values, skills and needs of potential adopters. Adoption and usage are rates higher when an innovation is compatibility to a user needs. This, therefore, creates a connection that allows the user to understand the innovation in a familiar context thus creating a relationship with the intention to use [44]. Therefore, compatibility is predicted to have a direct positive effect towards the intention to adopt and then a direct impact on actual usage. $\underline{\mathrm{Hi}}$ ) Compatibility will have a positive effect on older adult's behavioural intention to adopt and use Facebook. H5ii) Compatibility will have a positive effect on older adult's behavioural intention to adopt and use Twitter. Initial Trust: Trust is an important factor in several social and economic interactions, particularly interactions that exist between users and novel technologies, as it involves uncertainty and dependency[45] [46]. Most OSN users are aware of risks and threats associated with online activities, but no level of unease is reflected in their actual behaviour due to trust [43]. Thus, a formed hypothesis designed to affirm that a firm's reputation trust has a positive effect on OSNs adoption and usage. H6i). The level of initial Trust a person has in Facebook will positively influence behavioural intention to adopt and use Facebook. H6ii). The level of initial Trust a person has in Facebook will positively influence the continual usage of Facebook. H6iii). The level of initial Trust a person has in Facebook will positively influence behavioural intention to adopt and use Twitter. H6iv): The level of initial Trust a person has in twitter will positively influence the continual usage of Twitter. Primary Influence applied from the MATH theory is a source of influence from Family and friends. This is defined by Rice et al., [44] as the extent to which members considered to be within an individual's social network influence the individual's behaviour in adopting an innovation. IS research studies acknowledges that social influence is a contributing factor for acceptance of technology [45]. Therefore, this construct will be implemented in this research and is predicted to be a positive influence on the intention to adopt and actual usage. $H 7 i$ ): Primary Influence will have a positive effect on older adult's behavioural intention to adopt and use Facebook. H7ii): Primary Influence will have a positive effect on older adult's behavioural intention to adopt and use Twitter. Secondary Influence that is also applied from the MATH theory is a source of influence from outside the social circles (family and friends). It is defined as a means of influence towards adoption on individuals through Television, newspapers, and marketing personals [41]. Illegal activities on the internet in association with OSNs use is always presented through the media thus leading to a negative impact on potential users and actual users. Therefore, this hypothesis is designed to determine if the source of influence impends adoption and use of OSNs within the older adult's population. H8i): Secondary Influence will have a negative effect on older adult's behavioural intention to adopt and use Facebook. H8ii): Secondary Influence will have a negative effect on older adult's behavioural intention to adopt and use Twitter. Requisite Knowledge is the control belief structure that is a construct applied from the MATH theory. It is defined as the degree to which an individual believes he or she has sufficient knowledge to use an innovation [41]. With evident digital divide among the older adult's population, IT literacy required to perform certain tasks such as use a device and access OSNs may be lacking. The proposed hypothesis tests if the lack of Requisite Knowledge by an older adult can discourage adoption and use of OSNs. H9i) Requisite Knowledge will have a negative effect on older adult's behavioural intention to adopt and use Facebook. H9ii) Requisite Knowledge will have a negative effect on older adult's behavioural intention to adopt and use Twitter. Facilitating Conditions taken from the DTPB theory is grouped under two factors: Technology F.C and Resource F.C, which are defined as the degree to which several conditions such as cost, time and mobile devices are needed to make use of an innovation [39]. H10i) Technology F.C and Resource F.C will have a positive effect on older adult's behavioural intention to adopt and use Facebook. H10ii) Technology F.C and Resource F.C will have a positive effect on older 
adult's behavioural intention to adopt. Perceived Ease of Use is applied from MATH theory and defined as the degree to which an innovation is considered not difficult to understand and use [41]. In the context of this research, the hypothesis is designed to test the usability design of Facebook and Twitter, such as display text, colour, and perceived assistance in relation with ease of use among older adult's population. H11i) Perceived Ease of Use will have a positive effect on older adult's behavioural intention to adopt and use Facebook. H11iii) Perceived Ease of Use will have a positive effect on older adult's behavioural intention to adopt and use Twitter. The relationship between the hypothesis and the constructs led to a conceptual framework, which is shown in Figure 1.

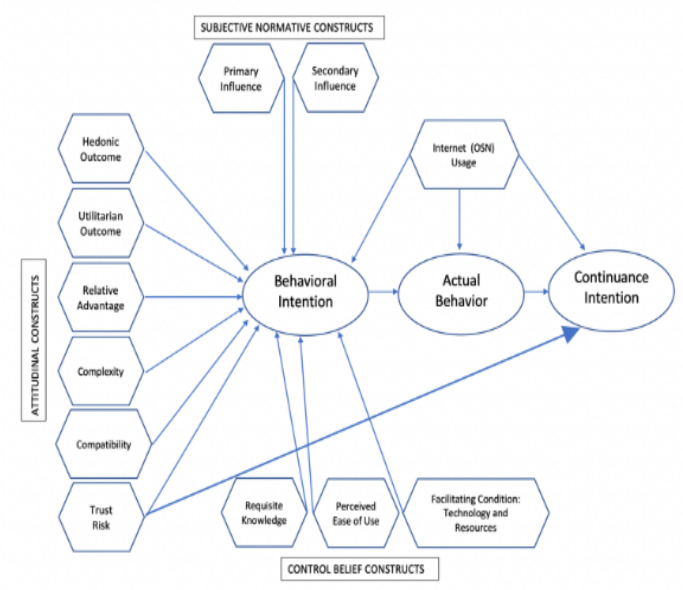

Figure 1. Conceptual Framework

\section{Research Methodology \\ 4.1. Research Approach and Research Sampling.}

As this research study is social sciences based, two research approaches were considered: a quantitative approach and qualitative approach. There are several research publications focused on the adoption, use and diffusion areas ([47];[48]) which led this team to conclude that the area of adoption, use and diffusion on its own is quite mature and employed a quantitative approach. A quantitative approach allows access to a larger and more diverse population and allows a conformation and contradiction of an idea; thereby allowing a study to test its hypothesis based on gathered evidence or data [48]. For this research study, data was gathered for 8 months using survey methods (use of online and hard copy questionnaires). The use of web surveys offers simple, fast and cheap access to a wider group of participants; thus, a record increase in the use of this method [49]. As older adults are low adopters of the internet, this study used different data collection techniques for the survey completions. This included the use of a hard copy (paper) that was sent via postal mail and used online questionnaires. Each medium (mail or internet) presented its own opportunities and challenges. The use of both sampling methods (probability and non-probability) was essential to ensure a successful data collection process. Simple random sampling (probability) and purposeful sampling (non-probability) was used to select towns /areas in Hertfordshire and households. Simple random sampling is the most popular method for choosing a sample among population for a wide range of purpose [50]. This removes bias as every member of the population is equally likely to be chosen. From 267 towns a random selection was used to obtain survey participants. Upon selection of the town, specific households were targeted. The selection criteria required for targeting households was that there should be residents 50 years old and above, which led to the use of non-probability sampling: purposeful sampling. Households selected for the survey received an invitation letter that provided an introduction description of the research topic and the researcher's backgrounds. Also contained in the introduction letter was a web-link to the online survey and contact details for the researchers.

\subsection{Research Site}

The selected research site of this study is Hertfordshire, which is the second largest county of East England in and located towards the north of London, UK. It is also a county in England that operates a two-tier structure; i.e. a county and district councils which makes it unique (Hertfordshire: 2021). The county consists of 267 towns, with more than 30 significant company headquarters in the county, representing sales of more than 1 billion. A strong economy worth $£ 32.8$ billion in 2014 , growing by $3.2 \%$ per year between 2004 and 2014 [51]. Employment in knowledge-based industries such as professionals, scientific and technical expertise in Hertfordshire have been on the rise at $+35.2 \%$ per growth between 2010-2015, higher than across England at $+33.9 \%$. The unemployment rate reduced to $3.5 \%$ in 2015 , which was a record in 10 years. Nevertheless, the working age population in Hertfordshire continues to increase to $0.8 \%$, faster than England's average which is at $0.4 \%$ [51]. Approximately $11.1 \%$ of the working age in Hertfordshire residents are self-employed towering over the other counties in England which is averaged to be at $9.7 \%$. Hertfordshire significantly grosses more value per head on goods and services, compared to East of England and UK average which shows it is an affluent part of the UK [52]. It is evident that the population of the UK is aging in terms of increase in the median age and the numbers of older adults of 
which Hertfordshire is one of the areas being affected by this issue [11]. In 2016, the county was rated as the second most densely populated county in the East of England with an estimated population of over 1.18 million people as at 2017 of which $33 \%$ represents older adults [53]. Life expectancy in Hertfordshire has been found to be above the national average and people continue to live longer because of the high standards of living and good quality of life the residents enjoy (Hertfordshire: 2021). Therefore, for the above-mentioned reasons and the fact that having access to this population area means that there is easier access to the population, all within a suitable time frame and cost; Hertfordshire was selected.

\section{Pilot Study}

\subsection{Pilot Study Design}

The pilot questionnaire consisted of 39 close ended, Likert scale questions (5 items) and included an invitation letter. To access the online survey, a web link was provided and shared on all OSN platforms. 3000 invitation letters were distributed to potential households targeting residences aged 50 and above. This led to a return of 266 responses, which amounts to an $8,7 \%$ return. Within external surveys, an acceptable rate is 10 to $15 \%$ [55]. Although our rate is $8.7 \%$ we have now learnt that for the next phase, we will need to ensure that our targeting of selected areas should be better developed to target residential homes and churches as well as affluent areas where older adults reside. Of the 266 replies, 189 participants used the online format, while 77 used the paper-format, face-to-face or telephone means. To ensure validation of our data, content validity was conducted of the questionnaire before distribution and collection of data. For this, we used an expert panel that included 13 industry experts, and 2 students. Research data cannot be scientifically accepted or considered valid without validation through tests. Therefore, a validity test was necessary to validate collected data and are detailed in the sections below.

\subsection{Content Validity and Construct Reliability}

Content validity focuses on whether the full content of a conceptual definition is represented in the measure [54]. The expert panel for the content validity form indicated that the questionnaire could be completed between 20 and 25 minutes on average. Participants were tasked with rating each survey question as one of the following options of Essential, Not essential and Not necessary. A cumulative number of responses then provided the $\mathrm{CV}$ ratio that led to elimination of several survey questions and a change of words within the survey that were considered vague for participants to understand. Constructs are not directly observable, as they are conceptual or theoretical entities [55]. For this pilot study, 39 questions were developed that represented 12 constructs drawn from literature and defined as shown in Table 1 below.

Table 1: Pilot Survey Construct Measures

\begin{tabular}{|c|c|c|c|}
\hline \multicolumn{4}{|c|}{ Pilot Survey Construct Measures } \\
\hline Construct & Definition & $\begin{array}{l}\text { Number of } \\
\text { items }\end{array}$ & Literature Source \\
\hline Hedonic Outcome & $\begin{array}{l}\text { Online social network leads to fun, entrainment } \\
\text { and enjoyment activities }\end{array}$ & 2 & $\begin{array}{l}\text { Venkatesh \& Brown, } \\
\text { (2001) }\end{array}$ \\
\hline Utilitarian Outcome & $\begin{array}{l}\text { Online social network enhances effectiveness of } \\
\text { activities (in households) }\end{array}$ & 2 & $\begin{array}{l}\text { Venkatesh \& Brown, } \\
\text { (2001) }\end{array}$ \\
\hline Relative Advantage & $\begin{array}{l}\text { The degree to which an innovation is technically } \\
\text { superior to the technology it supersedes }\end{array}$ & 2 & Taylor \& Todd (1995) \\
\hline Complexity & $\begin{array}{l}\text { Online social networks for potential adopter as } \\
\text { being relatively difficult to use and understand }\end{array}$ & 2 & (Rogers, 1995) \\
\hline Compatibility & $\begin{array}{l}\text { Online social networks is perceived compatible } \\
\text { with existing values, skills and needs of potential } \\
\text { adopters }\end{array}$ & 4 & Rogers, (2003) \\
\hline Trust & $\begin{array}{l}\text { Online social network interactions that exist } \\
\text { between users, potential adopters and social } \\
\text { media companies }\end{array}$ & 3 & $\begin{array}{l}\text { Wang and Benbasat, } \\
(2008)\end{array}$ \\
\hline Primary Influence & $\begin{array}{l}\text { Members within an individual's social circle ( } \\
\text { family, friends and colleague) use online social } \\
\text { network }\end{array}$ & 2 & $\begin{array}{l}\text { Venkatesh \& Brown, } \\
\text { (2001) }\end{array}$ \\
\hline Secondary Influence & $\begin{array}{l}\text { Possible influence from outside an individual's } \\
\text { social Circle; TV, Newspaper or radio influence } \\
\text { my choices on online social network }\end{array}$ & 2 & $\begin{array}{l}\text { Venkatesh \& Brown, } \\
\text { (2001) }\end{array}$ \\
\hline Requisite Knowledge & $\begin{array}{l}\text { The belief that he/she has the knowledge } \\
\text { necessary to use a PC. }\end{array}$ & 4 & $\begin{array}{l}\text { (Compeau \& Higgins, } \\
\text { 1995) }\end{array}$ \\
\hline Facilitating Condition & $\begin{array}{l}\text { The degree to which several conditions such as } \\
\text { cost and devices are needed to make use of an } \\
\text { innovation }\end{array}$ & 2 & Taylor \& Todd (1995) \\
\hline Perceived Ease of Use & $\begin{array}{l}\text { Online social network is considered not difficult } \\
\text { to understand and use }\end{array}$ & 2 & $\begin{array}{l}\text { Venkatesh \& Brown, } \\
(2001)\end{array}$ \\
\hline
\end{tabular}

For research, an estimate of each construct's reliability is needed, which is vital for internal consistency reliability and provided by several validity tests. For this, the Cronbach alpha and Average Variance Extracted (AVE) are important [55]. A valid Cronbach alpha and AVE result identify validity and are expected to be above 0.7 and 0.5 [56]. Table 2 shows that most of the constructs met the reliability measurement, except for the construct Complexity. Following validity, the next step identified whether the variables can be applied in real life; i.e. each construct has an indicator, which is identified by a question. For this purpose, factor loadings were required and calculated using the software SPSS. Each latent variable (construct) was linked to the indicators (question) used in the questionnaire. To be considered valid and applicable in real life, factor loadings or factor analysis should range between 0.7 to 0.9 . All the indicators (questions) showed a factor loading of 0.755 to 0.893 ; thereby, considered valid for use with a good consistency between the constructs. Having found that the constructs could be applied to this study, the next step involved analysing the results of the survey questionnaires, which are explained next. 
Table 2: Reliability Result values

\begin{tabular}{|l|l|l|}
\hline Hypothesis & Cronbach's Alpha & $\begin{array}{l}\text { Average } \\
\text { Variance (AVE) }\end{array}$ \\
\hline $\begin{array}{l}\text { Behavioral intention } \\
\text { (BI) }\end{array}$ & 0.889 & 0.297 \\
\hline Hedonic Outcome & 0.557 & 0.687 \\
\hline Utilitarian Outcome & 0.849 & 0.687 \\
\hline Relative Advantage & 0.575 & 0.698 \\
\hline Complexity & 0.437 & 0.636 \\
\hline Compatibility & 0.854 & 0.692 \\
\hline Trust & 0.526 & 0.678 \\
\hline Primary influence & 0.597 & 0.710 \\
\hline Secondary Influence & 0.655 & 0.742 \\
\hline Requisite Knowledge & 0.868 & 0.715 \\
\hline Facilitating condition & 0.604 & 0.713 \\
\hline Ease of Use & 0.597 & 0.708 \\
\hline
\end{tabular}

\section{Data Analysis}

6.1. Descriptive Data Analysis

Data collection was for 8 months, and led to 266 responses, of which 6 were considered invalid due to incomplete replies. The first section of the questionnaire determined the demographics of the sample population, which are explained next. Demographics: From our analysis there were 118 Male $(44.36 \%)$ and 148 Female $(55.64 \%)$ participants replies. Therefore, female participants outranked the males, which confirms the ONS (2018) findings of Hertfordshire that there are more female users than males. Hertfordshire is also an affluent area that offers many recreational facilities and a good healthcare service that accounts for $69.58 \%$, (183) participants indicating good health, $18.3 \%$ (49) participants indicating that they have an excellent health and $12.93 \%$ (34) indicating poor health. Hertfordshire offers good schooling that accounts for $23.02 \%$ (61 participants) indicating that they have GSCE and $21.89 \%$ (58 participants) indicating that they have Alevel qualifications. Internet Usage in Household: Older adult's Internet use and adoption have been reported to be on the rise by reports and other older adult research such as [57]. This proved to be the case as 260 participants indicated they use the internet in their household, while 2 indicated they do not. 81 (31.4\%) participants indicated that their service provider is Virgin media and a strong factor for use was communication (email) and use of a search engine (google). Internet users by Age: Participants aged 50 to 59 and 60 to 69 used the internet more than those who, are older (70 and above). This is an interesting discovery but confirms that when individuals are working ( 50 to 65 years old) they use the internet more often than when in retirement [58].

\subsection{Structural Model Analysis}

For further analysis of the constructs drawn from the theories, structural equation modelling (SEM) was pursued using the software Smart PLS. SEM allows researchers to simultaneously estimate and test theories using empirical data. To estimate structural equation models, partial least squares (PLS-SEM) was suitable for explaining variance and estimating path models consisting of more than 5 constructs [59].

\subsection{Coefficient of Determination $\left(R^{2}\right)$}

The coefficient of determination that is termed as $\mathrm{R}^{2}$ is the amount of variance that is explained in each of the predictor latent constructs, accounting for the relationship between two or more variables. From the conceptual framework, Behavioural Intention (BI), is identified as the main independent variable. For this study the $\mathrm{R}^{2}$ for $\mathrm{BI}$ was 0.619 . This meant that $61.9 \%$ of the variance for BI was explained by the factors predicting it, which are the constructs $(\mathrm{H} 1-\mathrm{H} 11)$. For Actual Use (AU) and Continuance Intention, the $\mathrm{R}^{2}$ shows a $49.9 \%$ and $69.1 \%$ variance respectively. This is based on the factors predicting it. $\mathrm{R}^{2}$ results hold different interpretations, depending on the values presented [60] where a significant value has a threshold of 0.8 to 0.7 while moderate is 0.5 and 0.3 is poor. Therefore, the independent variables of this study [BI, AU and $\mathrm{CI}$ ] revealed a significant $\mathrm{R}^{2}$.

\subsection{Path Coefficient}

Following the measurement of validity, boot strapping analysis was used to estimate the path coefficient, with a level of significance (alpha) set at 5\% (0.05). The path coefficient provides explanations of the effects of dependant variables on the independent variables. The values shown in Table 3 are the path coefficients. Boot strapping analysis also generates the t-values as subsamples are created with randomly drawn observations from the original data. For t-values, the level of significance is dependent on the set alpha, as mentioned alpha is set at $\mathrm{p}<0.5(0.05)$. The acceptable significance level expected considering it is a 2-T test analysis should be above 1.95 or approximately 2 to be considered valid [60]. 
Table 3. Hypothesis decisions based on T-value results

\begin{tabular}{|l|l|l|l|}
\hline $\begin{array}{l}\text { Variable } \\
\text { Path }\end{array}$ & T-value & Path Coefficient & $\begin{array}{l}\text { Hypothesis Decision } \\
\text { (Supported or Not- } \\
\text { Supported ) }\end{array}$ \\
\hline H1 $\rightarrow$ BI & 1.266 & 0.255 & Not-Supported \\
\hline H2 $\rightarrow$ BI & 12.74 & 0.321 & Supported \\
\hline H3 $\rightarrow$ BI & 3.423 & -0.083 & Supported \\
\hline H4 $\rightarrow$ BI & 7.262 & 0.165 & Supported \\
\hline H5 $\rightarrow$ BI & 0.531 & -1.151 & Not-Supported \\
\hline H6 $\rightarrow$ BI & 0.484 & 0.080 & Not-Supported \\
\hline H6 $\rightarrow$ CI & 9.366 & 0.547 & Supported \\
\hline H7 $\rightarrow$ BI & 12.29 & 0.231 & Supported \\
\hline H8 $\rightarrow$ BI & 2.515 & 0.473 & Supported \\
\hline H9 $\rightarrow$ BI & 5.351 & -0.009 & Supported \\
\hline H10 $\rightarrow$ BI & 0.616 & 0.126 & Not-Supported \\
\hline H11 $\rightarrow$ BI & 0.025 & 0.006 & Not-Supported \\
\hline BI $\rightarrow$ AU & 21.341 & 0.686 & Supported \\
\hline AU $\rightarrow$ CI & 6.219 & 0.359 & Supported \\
\hline
\end{tabular}

Table 3 shows the created hypothesis associations with the independent variables and whether they are applicable in real life. It was found that 7 hypotheses were supported and 4 were rejected. Utilitarian outcome [H2] showed a positive significance to BI for the adoption and use of OSNs. This confirms that older adults intended to use OSNs for effective (e.g. work) purposes as participant's replies indicated the use of Facebook for communication, while Twitter was used for current affairs [61]. Hedonic outcomes [H1] hypothesis was not supported, which meant that older adults do not consider Facebook or twitter as a platform for entertainment. Relative advantage [H3] also led to an intention to the adoption and use of OSNs, which meant that previous experiences with other innovative platforms could lead to adoption and use. The highest indicating factor for BI leading to Actual use is Primary Influence [H7], which suggests that the older adult's social network has a key role for the adoption and use of OSNs. Another key hypothesis to consider is Trust [H6], which is linked to both BI and AU. Findings revealed a weak relationship between Trust and BI that implied trust is not an important factor for the intention (BI) to adopting or using OSNs, but once adoption occurs, the intention to continue using OSNs is based more on trust; thereby leading to the conclusion that trust positively affects older adults continued use of OSNs, but it has no significance for the adoption or use of OSNs. Compatibility [H5], which is how well does an OSN fit in with an individual's lifestyle was not supported by the replies. Secondary influence that includes the use of media (newspapers, TV) [H8] and Requisite knowledge that is the required knowledge to use OSNs were both supported by the findings.

\section{Discussion}

There are diverse OSN platforms being offered daily, this research study showed 166 participants indicated using Facebook with other OSN (for example: LinkedIn, Twitter) simultaneously. 65 participants out of 266 indicated they use Twitter and other OSNs (for example: LinkedIn). When asked if the participants used only and solely Twitter or Facebook, 66 participants mentioned using only Facebook, while 4 participants used only Twitter. This suggests that older adults of Hertfordshire are using the classic OSN of Facebook versus Twitter and supports the view that Facebook is more popular within the general population [62]. As stated in the literature Facebook proved to be most popular followed by Twitter and then LinkedIn. Participants also indicated that they accessed OSNs, mostly in their homes rather than in a social environment such as a coffee-shop or work environment. This affirms the use of "household" context in this study, as several researchers have already indicated that households are where technology such as OSNs are predominantly used. However, we acknowledge that this is due to the age ranges that we have chosen; i.e. Above 50 years old. Empirical results from this study also showed that subjective norm was a critical factor influencing individuals to using OSNs, as social circle and television were highlighted as a source of influence towards the adoption and use of OSNs. However, other research articles focused on other ICTs and not OSNs [64] found subjective norm to be a noninfluential factor. From this study, the implications for academia are that models focused on adoption, use and diffusion of ICTs in households can be applied to understand OSNs adoption and use, but there are only certain factors that can be used. For instance, presently in the UK, trust is an important factor of consideration as OSN providers such as, Facebook are being warned about inappropriate use of the users' data. Our research shows that trust is vital for older adults, so policymakers should examine such issues. We also found that subjective norm is important for new users, so when governments are forming policies to increase OSNs use, they can use channels such as, individuals' social networks, classic communication channels such as, TV or newspapers.

\section{Conclusion and Future Direction}

The aim of this study was to identify, understand, examine and explain the adoption, use and diffusion of OSN: namely, Facebook and Twitter within the older population of UK. Using the models of MATH, DTPB, DOI, and TPB this study found that older 
adults use Facebook more than Twitter. We also found that OSNs are used for more effective purposes (communication) than for entertainment. They were also reliant on classic communication channels when considering adopting and using OSNs. Trust was also an important factor for the adoption and use of OSNs. This study is limited because it has a smaller sample population size, which cannot allow generalisations regarding the factors of adoption, use and diffusion. To overcome this, the future direction of this study is proposed to include a larger sample size that will be obtained using hard copy and online questionnaires. The unique contributions of this study are viewed to be the comparisons of a classic and recent OSN platform, which not many studies offer. Other benefits are viewed to be an understanding of factors leading to the adoption, use and diffusion of OSNs within older adults residing in a household in a certain vicinity of the UK.

\section{Reference}

[1] Hanna N.K. (2010) An ICT-Transformed Government and Society. Springer, New York, NY

[2]. Amichai-Hamburger, Yair and Zack Hayat. "The impact of the Internet on the social lives of users: A representative sample from 13 countries." Computers in Human Behavior 27 (2011): 585-589.

[3]. Yair A-Hamburger and G Vinitzky Social network use and personality. ScienceDirect (26) 1289-1295.

[4] Choudrie, J, Voros, T.Vyas, A and Tsitsianis, N. (2013) Comparing the Adopters and Non-Adopters of Online Social Networks: A UK perspective 46th Hawaii International Conference on System Sciences.

[5] Penni, J. 2017. The future of online social networks (OSN): A measurement analysis using social media tools and application. Journal of telematics and informatics 34(489-517).

[6] Statistics Portal (2017): The most famous social networks worldwide as of September 2016, ranked by number of active users (in millions).

[7] Statistics Portal (2017): The most famous social networks worldwide as of September 2016, ranked by number of active users (in millions).

[8] Damant, J., and Knapp, M. (2015) What are the likely changes in society and technology which will impact upon the ability of older adults to maintain social (extra-familial) networks of support now, in 2025 and in 2040? Foresight, Government Office for Science.

[9] NetLingo (2012) Silver Surfers: Definition Available at: $\underline{8}$.

[10] Albert MS, Heaton RK. (1988). Intelligence testing. In: Albert MS, Moss MB, editors. Geriatric Neuropsychology. New York: Guilford Press; pp. 13-32.

[11] Office of National statistics (ONS). 2017. Overview of UK population.

[12] Parliament Office of Science \& Technology. (2011). An Ageing Workforce. Available at: https://www.parliament.uk/pagefiles/504/postpn391_Agein g-Workforce.pdf
[13] Thomson, P. (2018). A silver lining for the UK economy: the intergenerational case for supporting longer working lives. Available at: https://www.ageingbetter.org.uk/sites/default/files/2018-02/Silver-lining-UKeconomy-crucial.pdf.

[14] National Institute of Economic and Social Research (2017), Older workers and the workplace: evidence from the Workplace Employment Relations Survey. Available at: https://www.gov.

uk/government/uploads/system/uploads/attachment_data/fil e/584727/older-workers-andthe-workplace.pdf.

[15] K. Vroman, S. Arthanat, C. Lysack, "Who over 65 is online?" Older adults' dispositions toward information communication technology". Computers in Human Behavior. (2015) 43 pp156-166.

[16] CABR, (2018). Older workers crucial to future of UK economy. Available at: https://www.ageingbetter.org.uk/news/older-workers-crucial-UK-economy . [17] OECD (2017). OECD Internet Economy Outlook 2012. Available at : https://dx.doi.org/10.1787/9789264086463-en [18] OFCOM (2018). The economic impact of broadband. Available at : https://www.ofcom.org.uk/research-anddata/telecoms-research/broadband-research/economicimpact-broadband

[19] P. Koutrompis (2018). The economic impact of broadband" evidence from OECD countries. Available at : https://www.ofcom.org.uk/_data/assets/pdf_file/0025/113 299/economic-broadband-oecd-countries.pdf

[20] OECD (2017). OECD Digital Economy Outlook 2017. Available at : https://doi.org/10.1787/9789264276284-en

[21] A., Belton. (2014). Social Networking in Recruitment. Packt: ISBN: 9781783000043.

[22] Lipsman A, Mudd G, Rich M, Bruich S. (2012). The power of 'like': how brands reach (and influence) fans through social-media marketing. Journal of Advertising Research, 52(1) 40- 52.

[23] Boyd d (2008) Why youth heart social network sites: the role of networked publics in teenage social life. In: Buckingham D (ed.) Youth, Identity, and Digital Media (The John D. and Catherine T. MacArthur Foundation Series on Digital Learning). Cambridge, MA: MIT Press, pp. 119142.

[24] Boyd d and Ellison NB (2008) Social network sites: definition, history, and scholarship. Journal of ComputerMediated Communication 13(1): 210-230.

[25] Niehaves, B. and Plattfaut, R. (2014). Internet adoption by the elderly: employing IS technology acceptance theories for understanding the age-related digital divide. European Journal of Information Systems, 23(6), pp. 708-726.

[26] Doong, S. H. and Ho Shu-C. (2012) The impact of ICT development on the global digital divide. Researchgate: 11(5):518-533.

[27] Organization for Economic Co-operation and Development OECD, (2011)

[28] Organization for Economic Co-Operation and Development (2011) Understanding the Digital Divide. Available at https://www.oecd.org/sti/1888451.pdf [29] van Dijk, J. A. G. M. (2005). The Deepening Divide: inequality in the information society. Thousand Oaks: Sage. [30] Niehaves, B. and Plattfaut, R. (2014). Internet adoption by the elderly: employing IS technology acceptance theories 
for understanding the age-related digital divide. European Journal of Information Systems, 23(6), pp. 708-726.

[31] S. Gadsby, "Facebook, Industry News, Social Network Marketing: Active users in Europe" (2010). Available at: [http://www.clickymedia.co.uk/2010/04/uk- facebookuser- statistics-april-2010/.

[32] Madden and K. Zickuhr, " $65 \%$ of online adults use social networking sites". (2011).

[33] C. Maier,S. Laumer and A. Eckhardt, "Technology adoption by elderly people-an empirical analysis of adopters and non-adopters of social networking sites". Theory-guided

34] Venkatesh, V., \& Brown, S. V. (2001). A longitudinal investigation of personal computers in homes: adoption determinants and emerging challenges. MIS Quarterly, 25, 71-102.

[35] Zhang, X.and Maruping. L.M. (2008) Household technology adoption in a global marketplace: Incorporating the role of espoused cultural values. Springer Science Media Information System Vol. 10 pp. 403-413.

[36] Lee, M-Chi. and Tsai, T-Ru. (2010) What Drives People to Continue to Play Online Games? An Extention of Technology Model and Theory of Planned Behavior. intl. journal of human-computer interaction, 26(6), 601-620

[37] Ajzen, I. and Madden, T. J. (1986). Prediction of goal directed behavior: Attitude, intentions and perceived behavioral control Journal of Experimental Social Psychology, 22, 453-474.

[38] Lange. P. Kruglanski. A. and Higgins. T (2012) Handbook of Theories of Social Psychology Volume 1 Sage Publications .

[39] Taylor, S., \& Todd, P. (1995a). Assessing IT usage: The role of prior experience. MIS Quarterly, 19, 561-570.

[40] Brown. S.A., Venkatesh, V. and Bala. H. (2006). Household Technology Use: Integrating Household Life Cycle and the Model of Adoption of Technology in Households. The Information Society. Vol. 22 pp. 205-218.

[41] Venkatesh, V., and Brown, S. V. (2001). A longitudinal investigation of personal computers in homes: adoption

determinants and emerging challenges. MIS Quarterly, 25, 71-102.

[42] Rogers, E.M (1995) Diffusion of Innovation Free Press, New York.

[43] Van Slyke, C., Belanger, F., \& Comunale, C. (2004). Factors influencing the adoption of Web-based shopping: The impact of trust. Database for Advances in Information Systems.

[44] Benbasat, Izak and Wang, Weiquan (2005) "Trust In and Adoption of Online Recommendation Agents," Journal of the Association for Information Systems: Vol. 6 : Iss. 3 , Article 4.

[45] Sonja Grabner-Kräuter \& Sofie Bitter (2015) Trust in online social networks: A multifaceted perspective, Forum for Social Economics, 44:1, 48-68,

[46] Rice, R. E., Grant, A. G., Schmitz, J., \& Torobin, J. (1990). Individual and network influences on the adoption and perceived outcomes of electronic messaging. Social Networks, 12(1), 27-55.

47] A.M. Kirik., A. Arslan., A. Centinkaya., and M. Gul. (2015). A Quantitative Research on the Level of Social Media Addiction among Young People in Turkey.
International Journal of Science Culture and Sport: 3(3) ISSN: 2148-1148.

[48] A. Bryman and E. Bell. (2007). Business Research Methods. $2^{\text {nd }}$ Edn. Oxford University Press: Oxford.

[49] Biffignandi S., Bethlehem J. (2012) Web Surveys: Methodological Problems and Research Perspectives. In: Di Ciaccio A., Coli M., Angulo Ibanez J. (eds) Advanced Statistical Methods for the Analysis of Large Data-Sets. Studies in Theoretical and Applied Statistics. Springer, Berlin, Heidelberg

[50] Gravetter, F.J \& Forzano, L.B. (2011) "Research Methods for the Behavioural Sciences" Cengage Learning p. 146

[51] Hertfordshire Local Enterprise Partnership (HELP). (2016). Hertfordshire Economic Outlook.

[52] Hertfordshire 2021: A Brighter Future. Available at: file://C:/Users/Jyoti\%20Choudrie/Downloads/REG\%201\%20\%20 Hertford-shire\%202021\%20-\%20A\%20Brighter\%20Future.pdf [53] Herts Insight (2018) 2016-based Population Projections Profile Selection: Hertfordshire Geo-type:

County. Available at http://atlas.hertslis.org/profiles/profile?profileId=1051\&amp;geoT ypeId=16\&amp;geoIds=E10000015 \#\#

[54] L.A. Palinkas., S. M. Horwitz, C. A., Green, Jennifer P. Wisdom, Naihua Duan, and Kimberly Hoagwood. (2015). Purposeful sampling for qualitative data collection and analysis in mixed method implementation research. Adm Policy Ment Health 42(5): 533-544.

[55] N. Lovasz and K.L. Slaney. (2013). What makes a hypothetical construct "hypothetical"? Tracing the origins and uses of the 'hypothetical construct' concept in psychological science. ScienceDirect. Vol.31(1).

[56] V. Vinzi, W. Chin, J. Henseler and H. Wang, Handbook of Partial Least Squares: Concepts, Methods and Applications. (2010). Springer. Germany.

[57] OFCOM (2019). Adults: Media use and attitudes report. Available at: https://www.ofcom.org.uk/ data/assets/pdf file/0021/149 124/adults-media-use-and-attitudes-report.pdf

[58] OFCOM (2019). Internet users' experience of harm online 2019

[59] M., Sarstedt, C. M. Ringle, D. Smith, R. Reams and J. F. Hair Jt. (2014). Partial least squares structural equation modelling (PLS-SEM): A useful tool for family business research. Journal of family business strategy vol.5 pp.105115.

[60] V. Vinzi, W. Chin, J. Henseler and H. Wang, Handbook of Partial Least Squares: Concepts, Methods and Applications. (2010).

Springer. Germany.

[61] J. Choudrie and A. Vyas (2014). Silver Surfers adopting and using Facebook? A quantitative study of Hertfordshire, Technological Forecasting and Social change. Vol 89 pp.293-305

[62] Forsey, C. (2019). Twitter vs. Facebook: Which Platform Should Your Business Be On? Available at: https://blog.hubspot.com/marketing/twitter-vs-facebook [64] T-h. Hsu, Y-s, Wang., and S-c Wen. (2006). Using decomposed theory of planned behaviour to analyse consumer behaviour intention towards mobile text message coupons. Journal of Targeting, Measurement and Analysis for Marketing. Vol. 14, 4, 309-324. 